\title{
Anti-Factor Xa Activity Measurement
}

National Cancer Institute

\section{Source}

National Cancer Institute. Anti-Factor Xa Activity Measurement. NCI Thesaurus. Code C98706.

The determination of the amount of anti-activated Factor X present in a sample. This test is used to monitor low molecular weight or unfractionated heparin levels in a biological specimen. 